\title{
Trade Credit, Bank Lending and Monetary Policy Transmission
}

\author{
Simona Mateut ${ }^{a, b}$, Spiros Bougheas ${ }^{a}$, Paul Mizen $^{a, * \dagger}$ \\ ${ }^{a}$ School of Economics, University of Nottingham \\ University Park, Nottingham, NG7 2RD, United Kingdom \\ ${ }^{b}$ University of Siena, Piazza San Francesco 7, 53100 Siena, Italy
}

October 2002

\begin{abstract}
This paper investigates the role of trade credit in the transmission of monetary policy. Most models of the transmission mechanism allow the firm to access only financial markets or bank lending according to some net worth criterion. In our model we introduce trade credit as an additional source of funding. We predict that when monetary policy tightens there will be a reduction in market and bank lending, and an increase in trade credit. This is confirmed with an empirical investigation of 16,000 manufacturing firms.

Key Words: Trade Credit, Bank Lending, Monetary Policy Transmission, Credit Channel

JEL Classification Codes: E44, E52

\footnotetext{
${ }^{*}$ Corresponding author. E-mail: lezpdm@nottingham.ac.uk

${ }^{\dagger}$ The first author acknowledges the financial support from Experian plc through the Experian Centre for Economic Modelling while a visiting scholar at the University of Nottingham. The third author is Deputy Director of the Experian Centre and is currently Jean Monnet Fellow at the European University Institute, Florence. We acknowledge beneficial comments from Frank Hahn, participants at the Scottish Economic Society Conference 2002, and the Portuguese Financial Network 2002. Any remaining errors are our own.
} 


\section{Introduction}

Recent research has ensured that market imperfections have a central place in the transmission of monetary policy through the credit channel. When there is imperfect information, alternative types of credit cannot be regarded as perfect substitutes and hence the choice of external finance on the part of the firm, and the availability and price of external funds offered by financial intermediaries will depend on factors such as the strength of firms' balance sheets. This has introduced the broad credit channel view, extensively surveyed in Gertler (1988), Hubbard (1995) and Kashyap and Stein (1994). Some firms with characteristics that prevent effective access to alternative markets for funds such as corporate paper or bond markets may be particularly dependent on bank finance under these circumstances and this gives rise to the bank lending channel.

It has been a characteristic of this literature to think of market finance and bank finance as the two available external finance options. For example theoretical research has been developed to allow bank lending and a capital market to co-exist even though the former is more expensive (see Besanko and Kanatas (1993), Bolton and Freixas (2000), Diamond (1991), Holmstrom and Tirole (1997), Repullo and Suarez (2000) and Hoshi, Kashyap and Scharfstein (1993)). In these papers, capital market imperfections mean that access is denied to the capital market for firms with a weak financial position. These models predict that periods of monetary tightening will mostly affect financially weak firms (usually small firms) by restricting their access to bank lending and will cause a proportionate decline in aggregate investment, which has been corroborated by disaggregated data in Gertler and Gilchrist (1994) and Oliner and Rudebush (1996).

In this paper we consider another important source of external finance for firms, namely trade credit. According to a Federal Reserve Board Study by Elliehausen and Wolken (1993) trade credit represents about $20 \%$ of non-bank non-farm businesses ' liabilities, and up to $35 \%$ of total assets. A later study by Rajan and Zingales (1995) calculated that trade credit represented $17.8 \%$ of total assets for all American firms in 1991. In many other countries, such as Germany, France and Italy, trade credit represents more than a quarter of total corporate assets. And in the United Kingdom 70 per cent of total short term debt (credit extended) and 55 per cent of total credit received by firms comprised trade credit (Kohler, Britton and Yates, 2000). Eigthy per cent of all firms use trade credit according to a review by Atanasova and Wilson 
(2002), and the scale of trade credit usage is much increased during periods of monetary contractions.

Meltzer (1960) was the first to suggest that a trade credit channel might be a substitute for the bank lending channel, but from a theoretical point of view the implications of trade credit for the broad credit channel view have not yet been explored. Existing theoretical works are mostly concerned with explaining the use of trade credit. For example, Ferris (1981) and Schwartz (1974) have suggested that trade credit provides transactions services to firms, and Cunat (2001) demonstrates that, in the context of limited enforceability of debts, firms may use both trade credit and bank credit when the supplier and the buyer engage in specific production processes. Other papers have explained why trade credit is extended at all. Jain (2001) argues that nonfinancial firms extend credit to their customers as intermediaries between banks and the ultimate buyers. This supports the conjecture of Biais and Gollier (1997) that the seller's provision of trade credit can provide a valuable signal to the banker that the buyer is worthy of credit, thus mitigating credit rationing. However, these papers do not explain what the consequences might be for corporate finance and monetary policy making if firms take up trade credit when other funds are inaccessible and this puts them at odds with the small empirical literature that attempts to address this question (cf Nielsen, 2002 and Kohler, Britton and Yates, 2000)

In this paper we tie in a theoretical model with the existing empirical evidence. In our theoretical model we incorporate trade credit, bank loans and market funding into a framework that has some similarities with Repullo and Suarez (2000). Like their model the existence of imperfections on the credit market means that firms have access to different sources of external funding according to their initial wealth level (in their case they consider wealth relative to the size of the investment project). We begin by allowing firms access to market finance and bank finance only, and find with Repullo and Suarez (2000), that wealthier firms borrow on the capital market, while intermediately wealthy firms get bank loans, and lower wealth firms fail to obtain any funding for their projects. When we introduce trade credit, firms with little wealth can find funding for their projects by accepting trade credit. Thus instead of a monetary contraction resulting in some firms being refused credit altogether as in our first model and that of Repullo and Suarez (2000), we find monetary tightenings bring about a reduction in total capital market finance and bank lending but trade credit increases to allow them to pursue their projects. As a result trade credit can smooth out the impact of tighten- 
ing monetary policy. In the final section of the paper we test our conjectures against data from a panel of 16,000 UK maufacturing firms and confirm that our model predictions are supported.

The rest of the paper is organized as follows. Section 2 presents the general theoretical model without trade credit. Section 3 brings in the trade credit and describes the new distribution of firms over the three credit sources. Section 4 analyzes the impact of a monetary policy tightening in both settings. Section 5 provides some empirical evidence that supports the theoretical predictions of the paper. Finally, section 6 concludes.

\section{The Model without Trade Credit}

Consider a two-sector economy with two dates $(t=0,1)$. The first sector is competitive and produces an intermediate input. Firms in this sector are not financially constrained. In the second sector there is a continuum of firms (indexed by $i$ ) that produce a final good using the intermediate input. These firms have an initial endowment of wealth, $W_{i}$ (measured in final good units) that differs across firms. Both types of producers are risk-neutral and only consume at $t=1$. At $t=0$, final good producers are also endowed with the following risky technology. They can use one unit of the intermediate good that, at $t=1$, will yield either $H$ units of the final good with probability $\alpha$ or $L(<H)$ units with probability $1-\alpha$. Alternatively, firms can invest their initial endowment in the market and earn the riskless gross interest rate $R(>1)$. The market for the intermediate good is competitive and all producers charge a price of $P$ units of the final good. The final good producers are financially constrained. We assume that $W_{i}$ is uniformly distributed on the interval $(0, P)$.

In the absence of capital market imperfections firms in the final good sector can borrow funds in the capital market at the riskless interest rate. We make the following assumption:

$$
\text { Assumption 1: } \alpha H+(1-\alpha) L-P R>0
$$

Assumption 1 states that the project is socially efficient. Therefore, all firms irrespective of their level of wealth would earn positive profits. However, due to costly verification of realized returns, firms have access to different sources of external funding. 
In this section we introduce only two lenders: capital markets and banks. The difference between the two relates to the extent each of them can verify the project returns in each state. Chant (1992) has established that debtor control is less effective in market finance because of dispersion of investors and of free-rider problems. Also banks usually have better information about their debtors. For simplicity, we assume that capital markets can not verify the projects' realized returns, while banks can but only by incurring a cost.

It is clear then that only firms whose total repayment (principal plus interest payment) is less than the payoff in the low state can have access to the capital market. All other firms have to borrow from banks. In other words, if $R\left(P-W_{i}\right) \leq L$ firms can repay their loans even if their realized return is equal to $L$ (riskless loans). These firms can borrow from the capital market at the riskless gross interest rate $R$. On the contrary, when the total repayment exceeds the payoff in the bad state $\left[R\left(P-W_{i}\right) \geq L\right]$ firms can only choose bank loans.

\subsection{The banks}

The banking sector is competitive. Since banks can verify the projects' realized returns they can offer loans to firms even when the repayment exceeds the return in the low state. Townsend (1979) has demonstrated that the optimal deterministic contract with commitment in this type of environment is the standard debt contract. Let $M_{i}$ denote the loan repayment in state $H$ that banks demand from a borrower with initial wealth $W_{i}$ and $R_{B i}$ the corresponding gross interest rate. Then, $R_{B i}\left(P-W_{i}\right)=(1-\alpha) L+\alpha M_{i}$. The optimal contract specifies that at $t=1$, if the state is $H$, borrowers repay $M_{i}$ to the bank and if the state is $L$ the banks verify and take the whole return. Let $V$ denote the total verification costs. We assume that these costs increase with the size of the loan ${ }^{1}: V=m\left(P-W_{i}\right)^{2}$, where $m$ is a constant. Competition in the banking sector implies that banks make zero profits:

$$
\pi_{B}=R_{B i}\left(P-W_{i}\right)-(1-\alpha) m\left(P-W_{i}\right)^{2}-R\left(P-W_{i}\right)=0
$$

where $R\left(P-W_{i}\right)$ denotes the opportunity cost of funds.

\footnotetext{
${ }^{1}$ According to this functional form, verification costs increase at an increasing rate with loan size. As we will show below this implies that the interest rates that banks charge are also increasing with loan size. Had we assumed a linear function, the interest rate would have been independent on loan size.
} 
From the expression of the banks' profits we can derive the gross interest rate charged per loan.

$$
R_{B i}=R+(1-\alpha) m\left(P-W_{i}\right)
$$

Equation (2) shows that different firms pay different interest rates. The lower the wealth level the higher the interest rate charged. Thus at a certain level of wealth the verifying costs become so high that the firm is not willing to pay the corresponding interest rate.

\subsection{The firms}

At $t=0$, firms decide whether to run their projects and earn either $H$ or $L$ (with probability $\alpha$ and $1-\alpha$, respectively) at the end of the period or rather place their wealth on the market at the riskless interest rate $R$. Assumption 1 guarantees that firms that can borrow from the capital market do run their projects. In what follows, we consider only the firms that need to borrow from banks. In order to run their projects they borrow from banks $\left(P-W_{i}\right)$ and pay an interest rate $R_{B i}$ on their loan ${ }^{2}$. Their profit function is given by:

$$
\pi_{f}=\alpha H+(1-\alpha) L-R_{B i}\left(P-W_{i}\right)
$$

Firms are profit maximizers. Therefore, they will choose to run the project if the net returns are higher than the amount they would get from investing their wealth on the capital market. This condition can be formalized as follows:

$$
\alpha H+(1-\alpha) L-R_{B i}\left(P-W_{i}\right) \geq W_{i} R
$$

We can state now the main result of this section.

Proposition 1 For $\alpha H+(1-\alpha) L-P R>(1-\alpha) m\left(\frac{L}{R}\right)^{2}$, there exist two cutoff values $\bar{W}$ and $W_{0}, \bar{W}>W_{0}$ such that borrowing from the capital

\footnotetext{
${ }^{2}$ This is another way to say that at the end of the period firms pay back $L$ in the bad state and $M$ in the good state.
} 
market is not possible for firms with wealth levels $W<\bar{W}$ and firms with wealth less than $W_{0}$ prefer not to run their projects; they invest in other firms' projects through the capital market. Firms with intermediate wealth levels borrow from banks.

Proof. Access to capital market requires $R\left(P-W_{i}\right) \leq L$. This implies that $W_{i} \geq P-\frac{L}{R}$. Therefore, the cutoff value above which firms can borrow from the capital market is

$$
\bar{W}=P-\frac{L}{R}
$$

The rest of the firms can only borrow from banks. Condition (4) implies that $W_{i}\left(R_{B i}-R\right)+\alpha H+(1-\alpha) L-P R_{B i} \geq 0$. Substituting in the expression of $R_{B i}$ given by (2) we get

$$
(1-\alpha) m\left(P-W_{i}\right)^{2}+P R-\alpha H-(1-\alpha) L \leq 0
$$

Denote by $W_{0}$ the value of $W_{i}$ for which the inequality binds. Simple algebraic calculations give the solution

$$
W_{0}=P-\sqrt{\frac{\alpha H+(1-\alpha) L-P R}{(1-\alpha) m}}
$$

The inequality at the beginning of the proposition ensures that $\bar{W}>W_{0}$. It states that, at the cutoff value between market and bank finance, net returns in the absence of capital market imperfections are bigger than verifying costs. It assures that at least in the close vicinity of $\bar{W}$ there are firms that take bank loans.

Proposition 1 states that $W_{0}$ is smaller than $\bar{W}$. We also want to make sure that $W_{0}$ is positive. This implies

$$
P>\sqrt{\frac{\alpha H+(1-\alpha) L-P R}{(1-\alpha) m}}
$$

Proposition 1 shows that the initial wealth level is critical when choosing between the two available sources of external finance. Firms with high levels 
of wealth $(W>\bar{W})$ prefer market funding, those with intermediate wealth levels $\left(W_{0}<W<\bar{W}\right)$ turn to bank funding, whilst lower wealth firms $(W<$ $W_{0}$ ) decide not to invest in their projects. The result directly corresponds to Proposition 1 in Repullo and Suarez (2000), although our model differs from theirs.

\section{The Model with Trade Credit}

In addition to borrowing from financial institutions, firms may obtain loans from their suppliers. Trade credit represents an important source of external finance for firms. Despite its unattractiveness in terms of $\operatorname{costs}^{3}$, firms do request this kind of credit, expressing their willingness to pay high interest rates for the use of short term financing. Moreover, it seems that firms use more trade credit when money is tight.

Several empirical studies have investigated how credit terms vary across industries. There have been found wide variations across industries but rather similar credit terms within industries. "We find little willingness to vary $[\mathrm{TC}]$ terms in lieu of product price changes or in response to a change in prevailing interest rates trade credit terms are stable over time" (Ng, Smith and Smith, 1999). "Within industries, the relationship between the two trading partners determines how strictly the credit terms are enforced. The implication is that once a supplier decides to extend trade credit he will continue to do so as a matter of policy" (Nielsen, 2002).

\subsection{The seller}

There exists a sufficiently large number of sellers in the market. Sellers are profit maximizers. They have enough wealth to produce the single good traded in the economy. The per unit cost of the intermediate good, measured in final good units, is equal to $C$. At $t=0$, firms approach the sellers and ask for the good; the sellers invest $C$ and produce the good instantly. Since $C<P$, sellers earn a profit of $(P-C)$ per unit sold.

Sellers can observe the realized returns of their customers' projects without incurring any cost. They have better information about their customers than banks do. This advantage arises from the fact that sellers and buyers

\footnotetext{
${ }^{3} \mathrm{An}$ indicator of the high cost of trade credit is the lost earnings of firms that do not use the early payment discounts.
} 
are mostly engaged in the same non-financial transactions. In such a case, sellers could decide to offer trade credit to firms in order to earn financial profits. Non-discrimination among buyers requires that all firms, irrespective of their level of wealth, pay the same interest rate for the trade credit offered by the seller. Therefore, sellers will charge the same interest rate to all their customers taking trade credit. Let $R_{T}$ denote the interest rate charged by the trade creditor.

Note that because sellers can observe their customers' payoffs the form of the financial contract is indeterminate. Then, without any loss of generality, we assume that the contract is the standard debt contract. ${ }^{4}$ If state $L$ occurs the seller appropriates everything at zero cost; if state $H$ occurs, the seller demands a repayment $M_{T i}$ that satisfies the following condition:

$$
R_{T}\left(P-W_{i}\right)=\alpha M_{T i}+(1-\alpha) L
$$

Then, at $t=0$, sellers offer trade credit. They will receive $W_{i}$ and offer one unit of the intermediate good. Therefore, the size of the loan will be $\left(P-W_{i}\right)$. The interest rate that the seller charges, $R_{T}$, defines a cutoff level of wealth, $\hat{W}$, such that all firms with $W_{i}>\hat{W}$, prefer to approach the banks. The firm with initial wealth $\hat{W}$ is indifferent between taking a bank loan or trade credit. Therefore,

$$
R_{T}=R_{B}(\hat{W})=R+(1-\alpha) m(P-\hat{W})
$$

where $R_{B}(\hat{W})$ denotes the interest rate that the bank would charge to a borrower with initial wealth $\hat{W}$.

Evidently $\hat{W}$ has to be higher than $W_{0}$. Suppose that the seller chooses $W_{0}$ by setting $R_{T}=R_{B}\left(W_{0}\right)$. The only firms that could take trade credit are these firms with initial wealth $W_{0}$, who are indifferent between bank loans and trade credit. Wealthier firms get better conditions from banks while poorer firms do not find bank loans attractive. As a consequence, in order for the trade creditor to be able to sell the good to other firms with wealth levels lower than $W_{0}$ the seller has to charge an interest rate lower than $R_{B}\left(W_{0}\right)$.

\footnotetext{
${ }^{4}$ This allows comparisons between the terms of bank loans and those of trade credit contracts.
} 
From (9) we see that the more the seller moves the cutoff level, $\hat{W}$, further away from $W_{0}$ (by offering a lower interest rate, $R_{T}$ ) the demand for trade credit increases. In fact, the demand increases for two reasons. Some of the firms that are eligible for loans from banks prefer trade credit and some of the firms that could not receive loans at all can nevertheless afford trade credit. Then, the interest rate $R_{T}$ defines another cutoff value, $W_{1}$, such that all firms with initial wealth levels in $\left(W_{1}, \hat{W}\right)$ receive trade credit. The cutoff value $W_{1}$ must satisfy the following condition:

$$
\alpha H+(1-\alpha) L-R_{T}\left(P-W_{1}\right)=W_{1} R
$$

Proposition 2 In the presence of trade credit, there exist three cutoff values $\bar{W}, \hat{W}$ and $W_{1}, \bar{W}>\hat{W}>W_{1}$ that differentiate among firms with respect to their source of external funding. Thus, firms with high levels of wealth $(W \geq \bar{W})$ borrow from the capital market, firms with wealth levels in the interval $(\hat{W}, \bar{W})$ borrow from banks, firms with levels of wealth in $\left(W_{1}, \hat{W}\right)$, accept trade credit, and firms with levels of wealth $W_{i}<W_{1}$ do not run their projects and invest in the capital market.

Proof. Proposition 1 shows that, in the model without trade credit, firms with wealth levels $W_{i}>\bar{W}$ obtain market funding, while firms with wealth levels inside the interval $\left(W_{0}, \bar{W}\right)$ take bank loans. With $\hat{W}>W_{0}$ we have to show that firms with wealth levels in $\left(W_{0}, \hat{W}\right)$ switch to trade credit. Since the interest rate these firms have to pay for accepting trade credit is $R_{T}=R_{B}(\hat{W})$, which is smaller than the interest rate the bank would charge them, they are better off switching to trade credit. The firm with the lowest level of wealth among those accepting trade credit earns as much by running the project as from investing its wealth in the capital market. Using (10) we find that

$$
W_{1}=P-\frac{\alpha H+(1-\alpha) L-P R}{R_{T}-R}
$$

Therefore, the seller maximizes profits on the interval $W_{1}-\hat{W}$. In choosing the two cutoff levels, the seller considers the extra profits earned from offering trade credit. Then, the seller's extra profits are given by

$$
\left\{\begin{array} { l } 
{ R _ { T } ( P - W _ { i } ) + R W _ { i } - P R } \\
{ R _ { T } ( P - W _ { i } ) + R W _ { i } - C R }
\end{array} \text { for firms with } \left\{\begin{array}{l}
W_{0}<W_{i}<\hat{W} \\
W_{1}<W_{i}<W_{0}
\end{array}\right.\right.
$$


Note that the opportunity cost is different between the two intervals. The first group of firms can borrow from banks, albeit at higher interest rates, and buy the good even in the absence of trade credit. Therefore, the seller by offering trade credit makes only an additional financial profit. For the second group of firms, the seller earns even higher profits. Without trade credit these firms cannot purchase the good. Offering trade credit the seller manages to sell the good to more firms. Therefore, the lower the interest rate the sellers charge the higher the demand for the intermediate good. The above intuition leads to the following result:

Proposition 3 In equilibrium all firms that do not have access to bank loans receive trade credit, $W_{1}=0$. The equilibrium trade credit interest rate satisfies the following condition: $P=\frac{\alpha H+(1-\alpha) L-P R}{R_{T}-R}$.

Proof. See the Appendix.

Up to this point, for simplicity we have assumed a uniform wealth distribution. This is why all firms have access to trade credit as sellers are better off holding receivables in their balance sheets and extending trade credit rather than making a higher financial profit by keeping interest rates high and selling to a smaller number of firms. Had we assumed a normal distribution, then some firms would not have had access to trade credit as the gains from lowering the interest rate (thus increasing the number of firms buying the intermediate good) might not be sufficient to compensate for the financial losses. Nevertheless, the general taxonomy of firms according to their source of funds is very robust to changes in the wealth distribution.

\section{Monetary Policy}

In this section, we consider the monetary policy implications of trade credit in our model. We examine the effects of an increase in the rate of interest (tighter monetary policy) on the taxonomy of firms according to their financial source.

\subsection{No Trade Credit}

We start the analysis by considering the simple model with only bank and market finance. Allowing for a monetary policy tightening, we observe that an increase in the riskless interest rate $R$ will impact on the level of the other 
interest rates in the economy ${ }^{5}$. Both cutoff values that define the intervals for market and bank borrowing shift to the right. Let $W_{0}^{\prime}$ and $\bar{W}^{\prime}$ denote the new cutoffs.

Proposition 4 In an economy without trade credit, an increase in the market interest rate $R$ increases both the threshold wealth level above which capital market financing is available and the threshold wealth level above which firms take bank loans. Fewer firms are eligible for market finance, and as a result market lending decreases. Bank lending also decreases if $\int_{W_{0}}^{W_{0}^{\prime}}\left(P-W_{i}\right) d W_{i}>$ $\int_{\bar{W}^{\prime}}^{\prime}\left(P-W_{i}\right) d W_{i}$.

Proof. From (5) we get

$$
\frac{\partial \bar{W}}{\partial R}=\frac{L}{R^{2}}>0
$$

Equation (6) defines the cutoff value below which bank loans are accepted. An increase in $R$ will lead to

$$
\frac{\partial W_{0}}{\partial R}=\frac{P}{2} * \sqrt{\frac{1}{(1-\alpha) m[\alpha H+(1-\alpha) L-P R]}}>0
$$

Total lending is decreasing because fewer firms borrow and run their projects.

If the total amount previously borrowed by these firms (that no longer have access to bank loans) is greater than the amount borrowed by the new bank debtors (those that previously had access to the capital market), then bank lending will decrease. This proves the last part of the proposition.

Our model predicts that a monetary tightening reduces market finance and may also reduce bank lending if the outflows to unfunded firms are greater than the inflows from previously market funded firms. ${ }^{6}$ Similar results are obtained by Repullo and Suarez (2000).

\footnotetext{
${ }^{5}$ Where a tightening of monetary policy results in an increase of the riskless interest rate.

${ }^{6}$ The reason for the last qualification is that the result depends on (a) the new cutoff values, and (b) the distribution of wealth. In the proposition the densities are absent from the intervals because they cancel out (uniform distribution).
} 


\subsection{Trade credit}

We now do the same kind of exercise including trade credit among the sources of external finance. In this case, all firms could obtain external finance and run their projects. A monetary tightening will change the taxonomy of firms according to their sources of external finance but leave total investment unchanged. Let $\hat{W}^{\prime}$ denote the new cutoff.

Proposition 5 An increase in the market interest rate $R$ increases both the threshold wealth level above which capital market is available and the threshold wealth level above which firms take bank loans. As a result, market lending goes down; bank lending also goes down if $\int_{\hat{W}}^{\hat{W}^{\prime}}(P-W) d w>\int_{\bar{W}^{\prime}}^{\bar{W}^{\prime}}(P-W) d w$, as before. In addition, trade credit increases since firms that cannot obtain bank finance will resort to trade credit following the arguments of Section 3.

Proof. According to Proposition (3) market lending decreases. Since the cutoff level above which firms take bank loans increases $\left(\frac{\partial \hat{W}}{\partial R}=\frac{1}{(1-\alpha) m}>0\right)$ if the amount borrowed by firms that switch to trade credit exceeds the the amount borrowed by firms that can no longer access the capital market then bank lending will also decrease.

As for trade credit, there are firms that abandon banks and turn to their suppliers for funding. On the other side of the cutoff all firms still take trade credit. $\left(\frac{\partial W_{1}}{\partial R}=\frac{\partial W_{1}}{\partial \hat{W}} * \frac{\partial \hat{W}}{\partial R}<0\right)$. Sellers earn most of their extra profits exactly from selling to the poorest firms. The interest rate they charge will always be such as to make the last firm indifferent between running its project and investing its wealth in the capital market.

The cutoff values are defined as functions of the cost of funds in the corresponding markets. Thus, the threshold level of wealth above which market finance is available is positively correlated with the riskless interest rate level. Therefore, an increase in $R$ will shift $\bar{W}$ to the right. At the same time, the threshold wealth level above which firms take bank loans increases. This is consistent with the credit channel view: an increase in the costs of external finance produces a flight to quality, i.e. there is a ranking of firms according to quality that ensures that the best customers obtain market finance, the middle ranked firms obtain bank credit and the lowest quality customers obtain trade credit. 


\subsection{Predictions}

Our model predicts that when there is no trade credit, market finance will decline and bank lending may also decline if the outflow of unfunded firms is greater than the inflow of formerly market-financed firms. In such a setting a monetary contraction will diminish bank lending and the relative amount of market finance.

When there is trade credit we obtain a different prediction. Market finance will decline and bank lending may also decline if the outflow of firms is greater than the inflow of formerly market-financed firms, as before, but firms that were previously unfunded may now obtain trade credit. Our model predicts that as bank lending is withdrawn from certain firms with low wealth, trade credit will take its place. Hence, in contrast to the model of Repullo and Suarez (2000), we take into account the fact that firms that used to obtain bank funding before the monetary tightening may continue to obtain funding through trade credit.

The implications of introducing trade credit are:

1) that the absolute level of trade credit taken up should increase in a period of monetary tightening as more firms find that their wealth level is insufficient to obtain bank lending.

If the net inflow from market finance is less than the outflow i.e. bank lending declines, then we also predict:

2) that the absolute level of bank lending may also decline as the number of firms with wealth levels sufficiently high to allow them to obtain market finance falls but by less that the number of firms that fail to obtain bank lending at all.

3) that the magnitudes of trade credit relative to total liabilities should increase while bank lending relative to total liabilities should decline in periods of tight monetary policy relative to looser periods;

4) that trade credit relative to bank lending should increase.

If the firms that face financial constraints are predominantly small firms (because small firms have insufficient wealth to reach the threshold for market or bank finance) then we should also observe

5) that smaller firms are affected more dramatically than large firms by a monetary tightening. That is during periods when monetary policy tightens, small firms' access to bank lending as opposed to trade credit should decline and therefore the ratios of trade credit to total liabilities or bank lending should increase. These effects should not be observed for firms that are 
larger (and therefore financially more healthy) because they should be able to meet the required thresholds even during tight monetary policy periods.

The next section examines the evidence from a panel of 16,000 manufacturing firms in the United Kingdom over the period 1990-1999.

\section{Empirical Evidence}

In this section we report empirical results that support the theoretical predictions of our model. To test the implications of the model we use a sub-sample of the FAME database, which covers all UK registered companies. This gives detailed balance sheet and financial information for about 1.3 million companies plus summarised information for a further 1 million companies. We construct a sample from the FAME database that allows us to analyse some aspects of the monetary transmission mechanism and to emphasise the role played by firms' financial position. The sample includes data about all active British companies that satisfy the following criteria:

- their main activity is in the manufacturing sector, according to 1992 UK SIC Code

- they were established prior to 1989 and have information up to 1999 or 2000 .

In addition we separate data for the period 1990-1992 when monetary policy was tightening, from data for the period 1993-1999 when it was loosening. This provides us with some initial information on manufacturing firms' access to market finance, bank lending and trade credit which can address some of the predictions that were made in the previous section. We average the data so that the reported figures are given in millions of pounds per annum in Table 1. Taking year averages helps to remove the distortions that arise from the arbitrary allocation of contracts between adjacent financial years.

\subsection{Descriptive Statistics}

First we find that the absolute level of trade credit taken up by manufacturing firms on average per year for the period of monetary tightening is higher than the same measure for periods of loosening monetary policy. This is given in column 2 of Table 1, where the ratio for the two periods is greater than unity. Second, and in contrast, average bank lending in each period shows the opposite. Bank lending was higher in the looser monetary period than 
in the tighter period, and this is shown by the ratio which is less than one. Thus the data confirm our first and second predictions.

Trade debit (trade credit offered) was lower in the tighter monetary period than subsequently, but the comparison between trade credit and trade debit (which is net trade credit reported in the final column) suggests that this was because manufacturing firms were offering more credit (not necessarily to other manufacturing firms) than they were receiving during the loose monetary policy period.

In Table 2 we compare the ratios. In column 1 we report the ratio between trade credit and bank lending, which almost halved when we compare the average per annum ratio for 1993-99 with 1990-92. This suggests that trade credit relative to bank lending was some 1.82 times higher in the tight period of monetary policy. Comparing the extent of trade credit to the sum of trade credit and bank lending we find a similar effect, although the magnitude is lower. The final two columns report the ratio of trade credit to total liabilities and the ratio of bank lending to total liabilities. In both cases the ratios behave as predicted since trade credit to total liabilities is much higher in the tight money period than subsequently, while for bank lending to total liabilities the ratio is lower. This confirms our third and fourth prediction.

\subsection{Estimation Results}

We estimate the relationship between the financial choices of firms and their specific characteristics using a standard panel model written in the following form:

$y_{i t}=\alpha_{i}+X_{i t} \beta+e_{i t}$

where $i=1,2, ., N$ refers to a cross section unit (firms in this study), $t=1,2, . ., T$ refers to time period. $y_{i t}$ and $X_{i t}$ are the dependent variable and the vector of non-stochastic explanatory variables for firm $i$ and year $t$, respectively. $e_{i t}$ is the error term, $\alpha_{i}$ captures firm-specific effects. We use a random effects approach, which treats $\alpha_{i}$ as a firm-specific disturbance. The nature of the data, which is drawn from a large population, makes the random effects model the most suitable approach for estimation, because it is more likely that firm specific constant terms are distributed randomly across cross-sectional units, that is, there is no correlation between firm specific constant terms and explanatory variables .

More specifically we can write the random effects model as follows:

$$
y_{i t}=X_{i t} \beta+\varepsilon_{i t}, \varepsilon_{i t}=\alpha_{i}+e_{i t}
$$


where $\varepsilon_{i t}$, the disturbance term, is made up of $\alpha_{i}$ representing an individual disturbance which is fixed over time and assumed to be uncorrected with explanatory variables and $e_{i t}$, an idiosyncratic disturbance. The estimation process involves unbalanced panel data techniques to test our hypothesis.

Tables 4 and 5 report the results of panel estimations of the effects of tight money on firms of different sizes to test prediction 5 . We use two measures of the monetary stance: the level of base rates and the sum of the changes to the base rate over the year - thus a positive sign implies increasing tightness, while a negative sign indicates loosening. However, we report only results for the level base rates. Similar results are obtained when the monetary policy tightness is measured by the cumulated sum of the change to the official interest rate during the year and are available at request. The years 1990-1992 were years of tightening, while 1993-1999 were years of loosening for the UK. The coefficients report the response of firms according to their size measured in two different ways. In Table 4 we report the results for firms classified by the official definition due to the Department of Trade and Industry based on the criteria indicated in Table 3, while in Table 5 we classify the firms by asset size to correspond to our theoretical prediction that their wealth is insufficient for them to qualify for financing of a given type. The use of the two different measures never alters the sign of the coefficients and only alters the significance in two cases out of 24 pairs of results.

The rows of each panel in the tables report the responses under tight and loose periods of monetary policy as defined above for firms of different sizes, altough the model takes into account other explanatory factors in the response of firms such as solvency, credit rating, coverage ratio, age, and sales to ensure that we report the marginal effect of monetary policy conditions and not the response (by proxy) for something else. In order to remove demand side effects we use ratios of one type of finance relative to another (see Kashyap, Stein and Wilcox, 1993). We discuss the Tables panel by panel below.

In panel 1 we find that trade credit increases relative to total short term debt (the sum of trade credit and bank lending) for all firm types in periods of tight monetary policy, and declines in loose periods. The responses are all significant, except for small firms in the loose money period, when the decline in response to loosening monetary policy is not significantly different from zero. The scale of the response is almost four times greater for small firms than for large firms in Table 4 and three and a half times larger in Table 5. Medium and large firms have responses that are much closer in scale in Table 
4 and 5. For a loosening policy, the response of small firms is insignificantly different from zero (lower interest rates do not induce an immediate reduction in trade credit taken up by small firms), but for medium and large firms they experience an identical decline in the ratio of a modest scale.

Panel 2 shows that trade credit relative to total liabilities also increases significantly with similar responses to panel 1 although the scale differences between small and medium/large firms are not so great. Again the response of medium and large firms is very similar, and the response of small firms to a loosening policy is insignificantly different from zero.

The response in bank lending is much more dramatic. Panel 3 shows a decline in the ratio of bank lending to total liabilities for small firms fifteen times greater than for large firms and seven and a half times greater than medium sized firms when interest rates rise. When interest rates fall, the increase in bank lending is also smaller for small firms than for medium and large firms. This provides compelling evidence for a bank lending channel that differentially and adversely affects small manufacturing firms.

These results support our fifth prediction and confirm that UK manufacturing firms, but especially the small firms with few assets, resort to trade credit when monetary policy tightens. The prediction of our model is upheld after we have conditioned for other factors that might explain the response to a change in monetary conditions such as solvency, age, credit rating, sales and demand factors.

In our model we cannot define exactly what the cutoff values for the critical wealth levels might be when we attempt to determine access to sources of finance of different types. The significant difference in the responses of small firms compared to medium and large firms to a tightening of monetary policy do suggest, however, that the cutoff for bank lending occurs somewhere between the size of small firms (less than 1.4 million pounds) and mediumsized firms (less than 5.6 million pounds). Small firms experience far less bank lending and more trade credit in tight periods of monetary policy than medium and large firms. This is verified using pairwise Chi-squared tests of coefficient equality in Table 6 . In all of the cases coefficients equality is rejected for small firms and large firms, and the same is true for small and medium sized firms with one exception. This exception relates to the bank lending ratio to total liabilities, where equality of the coefficients cannot be rejected, which is support for the argument that medium sized firms face an equivalent reduction in bank lending when interest rates increase. In two cases we confirm that the trade credit ratios for large and medium sized 
firms are identical. This evidence confirms that the responses are significantly different for small firms, where test statistics are very large, when compared to medium and large firms.

\section{Conclusions}

The paper analyzes the channel of monetary policy transmission when trade credit is included among the sources of external finance. Imperfections in the credit market allow only a few firms to borrow from the capital market at low (risk-free) interest rate. Banks cannot observe firms' returns costlessly and, therefore, charge their clients higher interest rates proportional to the amount that they lend. Since sellers have an information advantage over banks, they may have incentives to ameliorate credit conditions for borrowers and at the same time increase their profits. The credit market equilibrium in our model is characterized by high wealth firms borrowing from the capital market, intermediate wealth level firms borrowing from banks, and low wealth level firms taking trade credit. In this framework, we examine the consequences of a monetary policy change. We predict that a monetary tightening causes three main results: (a) a decrease in market finance and bank lending, if the outflows of firms seeking funds at the lower end of the wealth spectrum exceeds the inflows from the upper end; (b) an increase in trade credit as some firms are excluded from bank finance; and (c) a flight-to-quality effect for both capital market and bank borrowers. The results are consistent with the existing empirical literature that has identified a wider use of trade credit over periods of monetary tightening.

When we examine the evidence using panel data from 16,000 manufacturing firms in the UK we find that all our predictions are upheld. Bank lending declines in absolute and relative terms and trade credit increases. When we separate small firms from medium and large firms, and compare the responses over tight and loose monetary policy we find that it is the small (financially weaker firms) that are excluded from bank lending and these firms resort to trade credit. This is the case even when we take into account the effects of solvency, age, credit rating, sales and demand side effects. The magnitudes of the responses of small firms are many multiples of the responses of medium and large firms, which show practically identical responses. This suggests that the cutoff for bank lending (when asset levels are used to proxy firm size) occurs somewhere between the small and medium firm size. 
The model can be extended in a number of ways. First, for simplicity, in our model sellers have enough wealth to produce goods, and as long as their level of wealth is sufficiently high they can always borrow from the capital market, banks or other firms. Further extensions to the theoretical model could investigate the possibility that some firms may not even be able to receive trade credit and will simply fail. The effect of a monetary policy tightening on trade credit would then depend on the inflow of new demands for trade credit and the outflow of firms that simply file for bankruptcy, in much the same way as the effect of tightening on bank lending in this paper depends on the relative inflows and outflows of previously market financed and trade credit financed firms.

Second, the model suggests that financially constrained firms that are excluded from market finance and bank lending can still receive credit from other firms. This implies that the influence of a given increase in interest rates should have a more muted effect than if there is no alternative to bank finance. The existence of a substitute for bank lending weakens the influence of the credit channel to some degree, although trade credit is more expensive and is typically only held for the short term. If this is so, we should find that real responses to monetary tightening in investment and output are weaker than otherwise. Alternatively, we may find that monetary tightening must be more severe than otherwise in order to have the desired real effects. These are empirical issues that could be identified in the data. 


\section{References}

[1] Atanasova, C.V. and Wilson, N. 'Borrowing constraints and the demand for trade credit: evidence from UK panel data', Leeds University Business School, mimeo 2002

[2] Besanko, D. and G. Kanatas - 'Credit market equilibrium with bank monitoring and moral hazard', Review of Financial Studies 6, 213-232, 1993

[3] Bolton, P. and X. Freixas - 'Equity, bonds, and bank debt: capital structure and financial market equilibrium under asymmetric information', Journal of Political Economy 108, 324-351, 2000

[4] Biais, B. and C. Gollier - 'Trade credit and credit rationing', Review of Financial Studies, vol. 10, no. 4, 1997

[5] Chant, J.'The New Theory of Financial Intermediation.' in K. Dowd and M. K. Lewis (Editors) Current Issues in Financial and Monetary Economics. Basingstoke, Hampshire. Macmillan Education Ltd. pp. 4265, 1992.

[6] Cunat, V. -'Trade credit: suppliers as debt collectors and insurance providers', Financial Markets Group, London School of Economics Mimeo, 2001

[7] Diamond, D.- 'Monitoring and reputation: the choice between bank loans and directly placed debt', Journal of Political Economy 99, 689721,1991

[8] Elliehausen, G. and J. Wolken 'An empirical invetigation into motives for demand for trade credit', Federal Reserve Board Staff Study No 165.

[9] Ferris, J. - 'A transactions theory of credit use', Quarterly Journal of Economics vol. 96, pp. 243 - 270, 1981

[10] Gertler, M. - 'Financial structure and aggregate economic activity: an overview', Journal of Money, Credit and Banking 20, 559-588, 1988.

[11] Gertler, M. and S. Gilchrist - 'Monetary policy, business cycles, and the behaviour of small manufacturing firms', Quarterly Journal of Economics 109 (2), pp. 309-340, 1994 
[12] Holmstrom B. and J. Tirole - 'Financial intermediation, loanable funds and the real sector', Quarterly Journal of Economics 112, 663-691, 1997

[13] Hoshi, T., A. Kashyap and D. Scharfstein - 'The choice between public and private debt: an analysis of post-regulation corporate financing in Japan', NBER Working Paper No. 4421, 1993

[14] Hubbard, R.- 'Is there a 'credit channel' for monetary policy?', Federal Reserve Bank of St. Louis Review 63-77, 1995

[15] Jain, N. - 'Monitoring costs and trade credit', The Quarterly Journal of Economics and Finance, vol. 41, pp. 89-110, 2001

[16] Kashyap, A. and J. Stein - 'Monetary policy and bank lending', in N. Mankiw (ed.) Monetary Policy, The University of Chicago Press, Chicago, 1994

[17] Kashyap, A., J. Stein and D. Wilcox - 'Monetary policy and credit conditions: evidence from the composition of external finance', American Economic Review, vol. 83, 1993

[18] Kohler, M., E. Britton and T. Yates - 'Trade credit and the monetary transmission mechanism', Bank of England Discussion Paper, 2000

[19] Meltzer, A. H. - 'Mercantile credit, monetary policy, and the size of firms', Review of Economics and Statistics, vol. 42, pp. 429-437, 1960

[20] Ng, C. K., J. K. Smith and R.L. Smith - 'Evidence on the determinants of credit terms used in interfirm trade', Journal of Finance vol. 54, no. 3, pp. 1109-29, 1999

[21] Nielsen, J. - 'Trade credit and the bank lending channel', Journal of Money, Credit and Banking, vol. 34, no.1, 2002

[22] Oliner, S. and G. Rudebush - 'Is there a broad credit channel for monetary policy?', Federal Reserve Bank of San Francisco, 1996

[23] Rajan, R. and L. Zingales - 'What do we know about capital structure? some evidence from international data', Journal of Finance, vol. 50, pp. 1421-1460, 1995 
[24] Repullo, R. and J. Suarez - 'Entrepreneurial moral hazard and bank monitoring: A model of the credit channel', European Economic Review vol. 44,2000

[25] Schwartz, R.A. -' An economic model of trade credit', Journal of Economic and Quantitative Analysis, vol. 9, pp. 643-657, 1974

[26] Townsend, R. - 'Optimal contracts and competitive markets with costly state verification', Journal of Economic Theory, 21, pp. 265-295, 1979. 


\section{Appendix}

We can write the seller's maximization problem as:

$$
\underset{\hat{W}}{\operatorname{Max}}\left\{\begin{array}{c}
\int_{W_{0}}^{\hat{W}}\left[R_{T}\left(P-W_{i}\right)+R W_{i}-P R\right] d W_{i} \\
+\int_{W_{1}}^{W_{0}}\left[R_{T}\left(P-W_{i}\right)+R W_{i}-C R\right] d W_{i}
\end{array}\right\} \quad \text { s.t. } W_{1} \geq 0
$$

After simplifying the expressions, we write the Lagrangian:

$$
\mathcal{L}=\int_{W_{1}}^{\hat{W}}\left(R_{T}-R\right)\left(P-W_{i}\right) d W_{i}+\int_{W_{1}}^{W_{0}}(P-C) R d W_{i}+\lambda W_{1}
$$

where $\lambda$ denotes the Lagrangian multiplier. We take the derivative with respect to $\hat{W}$, taking into account that both $R_{T}$ and $W_{1}$ are functions of $\hat{W}$. The first order condition is then

$$
\begin{gathered}
\left(R_{T}-R\right)(P-\hat{W})-\frac{\partial W_{1}}{\partial \hat{W}}\left[\left(R_{T}-R\right)\left(P-W_{1}\right)+(P-C) R\right] \\
+\frac{\partial R_{T}}{\partial \hat{W}}\left[\left(P-W_{1}\right)^{2}-(P-\hat{W})^{2}\right]+\lambda \frac{\partial W_{1}}{\partial \hat{W}}=0
\end{gathered}
$$

There are two distinct cases: (1) $\lambda=0, W_{1}>0,(2) \lambda>0, W_{1}=0$.

1) In the first case the first-order condition becomes

$$
\begin{gathered}
\left(R_{T}-R\right)(P-\hat{W})-\frac{\partial W_{1}}{\partial \hat{W}}\left[\left(R_{T}-R\right)\left(P-W_{1}\right)+(P-C) R\right] \\
+\frac{\partial R_{T}}{\partial \hat{W}}\left[\left(P-W_{1}\right)^{2}-(P-\hat{W})^{2}\right]=0
\end{gathered}
$$

Using equations (9) and (11) and taking into account that $\frac{\partial W_{1}}{\partial \hat{W}}=\frac{\partial W_{1}}{\partial R_{T}} * \frac{\partial R_{T}}{\partial \hat{W}}$ we get

$$
\begin{gathered}
(1-\alpha) m(P-\hat{W})^{2}-\frac{(1-\alpha) m}{2} *\left[\frac{[\alpha H+(1-\alpha) L-P R]^{2}}{(1-\alpha)^{2} m^{2}(P-\hat{W})^{2}}-(P-\hat{W})^{2}\right] \\
+\frac{\alpha H+(1-\alpha) L-P R}{(1-\alpha) m(P-\hat{W})^{2}} *[\alpha H+(1-\alpha) L-P R+(P-C) R]=0
\end{gathered}
$$


Let $X=(1-\alpha) m(P-\hat{W})^{2}$ and $A=\alpha H+(1-\alpha) L-P R$. Equation (18) becomes

$X+\frac{A}{X} *[A+(P-C) R]-\frac{A^{2}}{2 X}+\frac{X}{2}=0$

Rearranging

$3 X^{2}+A *[A+2(P-C) R]=0$

Since $A>0$ and $X>0$ we have a corner solution because the first order condition is always positive for $W_{1}>0$.

2) In the second case, we have $\lambda>0, W_{1}=0$. Solving the first order condition we get the expression of $\lambda$. $W_{1}=0$ implies

$$
P-\frac{\alpha H+(1-\alpha) L-P R}{R_{T}-R}=0 .
$$

Therefore, $\alpha H+(1-\alpha) L=P R_{T}$. Using equation (9) we get

$$
\hat{W}=P-\frac{\alpha H+(1-\alpha) L-P R}{(1-\alpha) m P}
$$

The condition that $W_{0}$ be positive guarantees that $\hat{W}$ is greater than $W_{0}$. The condition (see Proposition 1) $\alpha H+(1-\alpha) L-P R>(1-\alpha) m\left(\frac{L}{R}\right)^{2}$ implies that $\hat{W}$ is lower than $\bar{W}$. 
Table 1

Scale of Trade Credit and Bank Lending 1990-1999, UK Manufacturing Firms (£ millions per annum)

\begin{tabular}{|c|c|c|c|c|}
\hline years & $\begin{array}{c}\text { average trade } \\
\text { credit (TC) }\end{array}$ & $\begin{array}{c}\text { average bank } \\
\text { lending (BL) }\end{array}$ & $\begin{array}{c}\text { average trade } \\
\text { debt (TD) }\end{array}$ & $\begin{array}{c}\text { net trade } \\
\text { credit (NTC) }\end{array}$ \\
\hline$(1) 1990-92$ & 79.9 & 75.6 & 87.5 & 7.63 \\
\hline$(2) 1993-99$ & 67.1 & 114.7 & 93.6 & 26.7 \\
\hline Ratio $(1) /(2)$ & 1.19 & 0.66 & 0.93 & 0.29 \\
\hline
\end{tabular}

Table 2

Ratios of Trade Credit to Bank Lending 1990-1999, UK Manufacturing Firms

\begin{tabular}{|c|c|c|c|c|}
\hline Years & TC/BL & TC/(TC+BL) & TC/Liabilities & BL/Liabilities \\
\hline (1) $1990-92$ & 1.06 & 0.51 & 0.25 & 0.24 \\
\hline (2) $1993-99$ & 0.58 & 0.37 & 0.16 & 0.28 \\
\hline Ratio $(1) /(2)$ & 1.82 & 1.38 & 1.56 & 0.86 \\
\hline
\end{tabular}

Table 3

Size categories firms

(two out of three criteria should be satisfied)

\begin{tabular}{|c|c|c|}
\hline Years & Small & Medium \\
\hline Turnover & $\max £ 2.8 \mathrm{mil}$ & $\max £ 11.2 \mathrm{mil}$ \\
\hline Balance sheet & $\max £ 1.4 \mathrm{mil}$ & $\max £ 5.6 \mathrm{mil}$ \\
\hline Ratio $(1) /(2)$ & $\max 50$ & $\max 250$ \\
\hline
\end{tabular}

Source: DTI 
Table 4

Response of Trade Credit Ratios to a Monetary Policy Tightening (1990-1992) versus Loosening (1993-1999) according to Size (DTI definition)

\begin{tabular}{|l|l|l|l|}
\hline monetary stance & small & medium & large \\
\hline \multicolumn{4}{|c|}{} \\
\hline Ratio: Trade Credit / (TradeCredit + BankLoans) \\
\hline Tight & $0.0371^{* * *}$ & $0.0127^{* * *}$ & $0.0092^{* * *}$ \\
& $(0.0017)$ & $(0.0009)$ & $(0.0007)$ \\
\hline Loose & -0.0018 & $-.0063^{* * *}$ & $-0.0067^{* * *}$ \\
& $(0.0025)$ & $(0.0015)$ & $(0.0015)$ \\
\hline \multicolumn{4}{|c|}{} \\
\hline Ratio: Trade Credit /Total Liabilities \\
\hline Tight & $0.0314^{* * *}$ & $0.0153^{* * *}$ & $0.0 .143^{* * *}$ \\
\multicolumn{5}{|l|}{$(0.0016)$} & $(0.0008)$ & $(0.0005)$ \\
\hline Loose & -0.0009 & $-0.0026^{* * *}$ & $-0.0011^{* * *}$ \\
& $(0.0018)$ & $(0.001)$ & $(0.0008)$ \\
\hline Ratio: Bank Lending/ Total Liabilities \\
\hline Tight & $-0.0245^{* * *}$ & $-0.0033^{* * *}$ & $0.0016^{* * *}$ \\
& $(0.0012)$ & $(0.0006)$ & $(0.0005)$ \\
\hline Loose & $0.0032^{*}$ & $0.0056^{* * *}$ & $0.0079^{* * *}$ \\
& $(0.0019)$ & $(0.0012)$ & $(0.0012)$ \\
\hline
\end{tabular}




\section{Table 5}

Response of Trade Credit Ratios to a Monetary Policy Tightening (1990-1992) versus Loosening (1993-1999) according to Size (definition based on assets only)

\begin{tabular}{|l|l|l|l|}
\hline monetary stance & small & medium & large \\
\hline \multicolumn{4}{|c|}{} \\
\hline Ratio: Trade Credit / (TradeCredit + BankLoans) \\
\hline Tight & $0.0347^{* * *}$ & $0.0164^{* * *}$ & $0.0101^{* * *}$ \\
& $(0.0018)$ & $(0.001)$ & $(0.0007)$ \\
\hline Loose & -0.001 & $-.0079^{* * *}$ & $-0.008^{* * *}$ \\
& $(0.0026)$ & $(0.0016)$ & $(0.0014)$ \\
\hline \multicolumn{4}{|c|}{} \\
\hline Ratio: Trade Credit /Total Liabilities \\
\hline Tight & $0.0304^{* * *}$ & $0.017^{* * *}$ & $0.0146^{* * *}$ \\
\multicolumn{5}{|l|}{$(0.0017)$} & $(0.0009)$ & $(0.0005)$ \\
\hline Loose & -0.0023 & $-0.0025^{* *}$ & $-0.002^{* * *}$ \\
& $(0.0019)$ & $(0.001)$ & $(0.0007)$ \\
\hline Ratio: Bank Lending/ Total Liabilities \\
\hline Tight & $-0.0226^{* * *}$ & $-0.007^{* * *}$ & $0.0012^{* * *}$ \\
& $(0.0012)$ & $(0.0007)$ & $(0.0005)$ \\
\hline Loose & 0.002 & $0.0066^{* * *}$ & $0.0089^{* * *}$ \\
& $(0.0019)$ & $(0.0012)$ & $(0.001)$ \\
\hline
\end{tabular}


Table 6

Chi-square test of Equality of Coefficients (DTI definition)

\begin{tabular}{|l|l|l|l|}
\hline monetary stance & small vs large & small vs medium & medium vs large \\
\hline \multicolumn{4}{|l|}{} \\
\hline Ratio: Trade Credit / (TradeCredit + BankLoans) \\
\hline Tight & 362.42 & 248.69 & 14.08 \\
& 0.0000 & 0.000 & 0.0009 \\
\hline Loose & 77.64 & 28.96 & 4.27 \\
& 0.0000 & 0.0000 & 0.1182 \\
\hline \multicolumn{4}{|l|}{} \\
\hline Ratio: Trade Credit /Total Liabilities \\
\hline Tight & 368.50 & 169.61 & 2.74 \\
\multicolumn{5}{|l|}{0.0000} & 0.2546 \\
\hline Loose & 0.0000 & 15.28 & 60.21 \\
& 154.58 & 0.0005 & 0.0000 \\
\hline \multicolumn{5}{|l}{} \\
\hline Ratio: Bank Lending/ Total Liabilities \\
\hline Tight & 0.000 & 290.70 & 65.01 \\
& 0.0000 & 0.0000 & 0.0000 \\
\hline Loose & 8.32 & 2.19 & 12.41 \\
& 0.0156 & 0.3345 & 0.0020 \\
\hline
\end{tabular}

